\title{
Response to the letter: Pregnancy outcomes in older women
}

\author{
Deepa Janga $\cdot$ Maud Nauta $\cdot$ Wai Yoong
}

Published online: 19 June 2014

(C) Springer-Verlag Berlin Heidelberg 2014

\section{Dear Sir,}

We would like to thank Drs Kim and Lee for sharing their data from a Korean population of older women [1]. They report preterm delivery rates of $8.5 \%$ for women $40-49$ years old versus $3.4 \%$ for those 20-24 years old, which is similar to our finding that older mothers were four times more likely to have births under 36 weeks. The threefold increase in delivery in Korean women $>35$ years old age, also mirror a trend of delaying pregnancy that is prevalent in America [2] and United Kingdom [3].

While the Korean data is interesting, we wonder why the authors did not provide data on assisted conception rates and if this had an impact on maternal age at delivery and proportion of multiple pregnancy and premature delivery. So far child health research has mostly considered maternal, but rarely paternal, education as a risk factor for many outcomes. In an American population based survey [4] paternal education remained significantly associated with preterm birth after controlling separately for maternal education, family income, and racial or ethnic group, the odds of preterm birth were higher for fathers who had not completed college when compared with college graduates.

In the United Kingdom, there has been almost a two fold increase in mothers over the age of 35 years [5] and the recent advice from the Royal College of Obstetricians and Gynaecologists via its Scientific Impact Paper [6] is being met with differing opinions. As rising maternal age is

\section{Janga $\cdot$ W. Yoong $(\bowtie)$}

Department of Obstetrics and Gynaecology,

North Middlesex University Hospital, London, UK

e-mail: waiyoong@nhs.net associated with higher maternal co-morbidities and obstetric complication rates, the 2013 Scientific Impact Paper raised the question of whether clinicians should offer routine induction of labour between 39 and 40 weeks gestation to older mothers. The paper also cited that epidemiological studies indicate older mothers $>40$ years had a late stillbirth risk at 39 weeks equivalent of younger mothers at 41 weeks. However, the effects of elective induction of labour before 40 weeks in older mothers on caesearean section rates will need to be balanced against potential reduction in late intrauterine deaths.

We would welcome other clinicians' opinions on this matter.

Conflict of interest None.

\section{References}

1. Kim TH, Lee HH (2014) Pregnancy outcomes in older mothers. doi:10.1007/s00404-014-3298-1

2. Schoen C, Rosen T (2009) Maternal and perinatal risks for women over 44-a review. Maturitas 64:109-111

3. National Statistics Online-Product, Office for National Statistics (ONS) (2011) Annual, online edition, characteristics of mother 1 2009: 21/10/10 (Table 2). Available from www.statistics.gov.uk/statbase/Product.asp?vlnk=14408. Cited 13 Feb 2011

4. Philip MB, Susan AE, Moreen LL, Paula AB (2011) Father's education: an independent marker of risk for preterm birth. Matern Child Health J 15(1):60-67

5. Centre for Maternal and Child Enquiries (2011) Saving mothers' lives: reviewing maternal deaths to make motherhood safer: 2006-8. Eight report on confidential enquiry into maternal deaths in the United Kingdom. BJOG 118(Supp 1):1-203

6. Induction of labour at term in older mothers. RCOG Scientific Impact Paper no 34. Feb 2013

M. Nauta

Camden Health Improvement Practice, Camden, London, UK 